\title{
Unexpected Thermal Decomposition Behavior of Poly( $N$-vinylimidazole)-l-Poly(tetrahydrofuran) Amphiphilic Conetworks, a Class of Chemically Forced Blends
}

\author{
Csaba Fodor, $*^{a}$ János Bozi $^{b}$ Marianne Blazsó ${ }^{b}$ and Béla Iván ${ }^{a}$
}

The underlying chemical processes of the unexpected thermal decomposition behavior of poly $(N$-vinylimidazole)- $l$-poly(tetrahydrofuran) (PVIm- $l$-PTHF) amphiphilic conetworks (APCNs) as chemically forced blends of the otherwise immiscible components in broad composition ranges were investigated by thermogravimetric analysis (TG) and thermogravimetry-mass spectrometry (TG-MS). Surprisingly, the thermal decomposition of these conetworks occurs not by an expected two-stage but an apparently single-stage process. The homolytic scission of the PTHF cross-linkers is preceded by a less significant volatile evolving by a non-radical reaction, presumably related to the well-known cis-elimination of the methacrylate ester linkages. The temperatures of the highest weight loss rate $\left(T_{\mathrm{d}(\max )}\right)$ were found to fall between that of the pure PVIm and PTHF homopolymers, and a universal correlation exists between $T_{\mathrm{d}(\max )}$ and the composition of the conetworks. The main thermal decomposition reactions of the polymer components in the PVIm- $l$-PTHF APCNs remain the same as in the corresponding homopolymers. However, among the two main degradation reactions of PVIm, the free radical depolymerization is promoted by PTHF macroradicals of molecular vicinity via hydrogen abstraction, which results in PTHF chains with improved stability. In contrast to expectations, this leads to a single-stage decomposition process of the two chemically interacting polymers in the conetworks. These results are expected to contribute to designing a variety of bi- and multicomponent polymeric materials with predictable thermal behavior composed of chemically and physically interconnected polymer chains, ranging from polymer blends to networks, block copolymers, composites and hybrids from the nanoscale to macroscopic objects.

\section{Introduction}

Imidazole (Im) is one of the most important heterocyclic aromatic compounds due to its presence in the most essential biomacromolecules, such as nucleic acids and proteins. The application fields of imidazole-containing synthetic polymers and its derivatives are of great current interest, such as component in fuel cells, ${ }^{1}$ ion imprinted and metal ion complexing matrices, ${ }^{2}$ catalyst and catalyst supports, ${ }^{3}$ corrosive protective coatings, ${ }^{4}$ electrophoresis medium, ${ }^{5}$ additive in wine production, ${ }^{6}$ enzyme immobilization carrier, ${ }^{7}$ gene delivery vectors, ${ }^{8}$ biomaterials with various pharmacological activities ${ }^{9}$ and artificial enzymes. ${ }^{10}$ In a previous study by us $^{11}$ the characterization of the thermal properties, behavior and unique degradation mechanism of poly( $N$-vinylimidazole) (PVIm) homopolymer were reported on the basis of the combination of different thermal analysis methods. However, detailed thermal stability and decomposition investigations on PVIm-containing bi- and multicomponent polymer systems are lacking. Herein, we report on the unexpected thermal behavior of $\operatorname{poly}(N-$ vinylimidazole)- $l$-poly(tetrahydrofuran) (PVIm-l-PTHF) (" l" stands for "linked by") amphiphilic conetworks (APCN).
Poly(tetrahydrofuran) (PTHF) (poly(tetramethylene oxide)) is widely used as soft segments in thermoplastic elastomers (polyesters and polyurethanes) in several block copolymers and cross-linked network structures, ${ }^{12}$ although the homopolymer itself has negligible commercial utility. PTHF is prepared by cationic ring opening polymerization (CROP) of tetrahydrofuran (THF) as monomer. ${ }^{13}$ The CROP allows to prepare end-group functionalized PTHF with well-defined average molecular weight and narrow molecular weight distribution. ${ }^{12,13}$ In contrast to PVIm, the thermal behavior of PTHF and PTHF consisting polymer structures have been studied by various methods. ${ }^{14}$

Combining these two polymers, that is PVIm and PTHF into covalently bonded mutually interconnected network results in a cross-linked structure (conetwork) with interesting characteristics and properties, such as unique phase separation, swelling in both hydrophilic and hydrophobic solvents, unprecedented glass transition and crystallization behavior etc. ${ }^{12 \mathrm{f}-\mathrm{h}}$ Such cross-linked polymer conetwork structures, in particular amphiphilic conetworks (APCNs), consisting of covalently bonded immiscible hydrophilic and hydrophobic cross-linked polymer chains have received significant interest 
in recent years. ${ }^{15}$ In addition to synthesis and application oriented research ranging from biomaterials and drug release matrices to nanohybrids, ${ }^{15,16}$ considerable investigations have also been carried out by a variety of techniques, such as differential scanning calorimetry (DSC), small angle x-ray scattering (SAXS), small angle neutron scattering (SANS), transmission electron microscopy (TEM), atomic fore microscopy (AFM) and solid-state NMR, on the miscibility and evolving structure of the macromolecular components in the conetworks indicating nanophase separation in these unique class of materials. ${ }^{16}$ However to the best of our knowledge, systematic investigations on the thermal decomposition of polymer conetworks have not yet been reported.

The thermal stability of PVIm- $l$-PTHF conetworks is of special importance considering potential high temperature applications of these materials. Taking into account the bond energy values of both polymers, the $\mathrm{C}-\mathrm{O}$ bond $\left(322 \mathrm{~kJ} \mathrm{~mol}^{-1}\right)$ in the backbone of the PTHF cross-linker is weaker ${ }^{14 \mathrm{~d}, 17}$ than the $\mathrm{C}-\mathrm{C}$ bond (346 $\mathrm{kJ} \mathrm{mol}^{-1}$ ) in the backbone of the PVIm. In PTHF, the C-O bond scission results in macroradicals stabilized by disproportionation or by hydrogen abstraction and elimination. ${ }^{14 \mathrm{~d}, 18}$ The random radical cleavage leads to some monomer (THF) and various homologous series of oligomers terminated mostly by aldehyde and $n$-butylether groups. In PVIm, the thermal decomposition occurs by nearly simultaneous imidazole formation by $\mathrm{C}-\mathrm{N}$ bond and random $\mathrm{C}-$ $\mathrm{C}$ bond homolytic scission along the backbone initiating a free radical chain reaction leading to $1 H$-imidazole and to 1 vinylimidazol (VIm) monomer, respectively. ${ }^{11}$ Herein, we report on the results of our investigations aiming at to reveal the influence of composition and molecular weight of the polymer components on the thermal decomposition of the conetworks based on PVIm cross-linked by methacrylate-telechelic PTHFDMA bis-macromonomers.

\section{Results and discussion}

For the synthesis of PVIm- $l$-PTHF amphiphilic conetworks, which can be considered as chemically forced blends between immiscible polymer chains, radical copolymerizations of the hydrophilic $N$-vinylimidazole (VIm) with hydrophobic poly(tetrahydrofuran) dimethacrylate (PTHFDMA) bismacromonomer were carried out as shown in Scheme 1 by using various feed ratios in ethanol, a cosolvent for all components (VIm, PVIm and PTHF) with AIBN as initiator under nitrogen atmosphere at $65^{\circ} \mathrm{C}$. Feed compositions with 30 to $80 \mathrm{wt} \%$ of PTHFDMA cross-linker were applied to achieve a broad composition range. Successful conetwork syntheses were confirmed by relatively low amounts of extractables in the range of $4-24.5 \% .^{12 \mathrm{e}}$ As the data indicate in Table 1, three series of conetworks, denoted as V2k, V7k and V10k, containing PTHFDMA with $M_{\mathrm{n}}$ of 2200, 6800 and $10000 \mathrm{~g} \mathrm{~mol}^{-1}$, respectively, were obtained over a broad composition range, i.e. with 25-91 wt\% PTHF content (the additional number in sample identification stands for the PTHF content in wt $\%$, i.e. V7k-52 denotes a PVIm- $l$-PTHF sample with $52 \mathrm{wt} \%$ PTHF of $\left.M_{\mathrm{n}}=6800 \mathrm{~g} \mathrm{~mol}^{-1}\right)$.

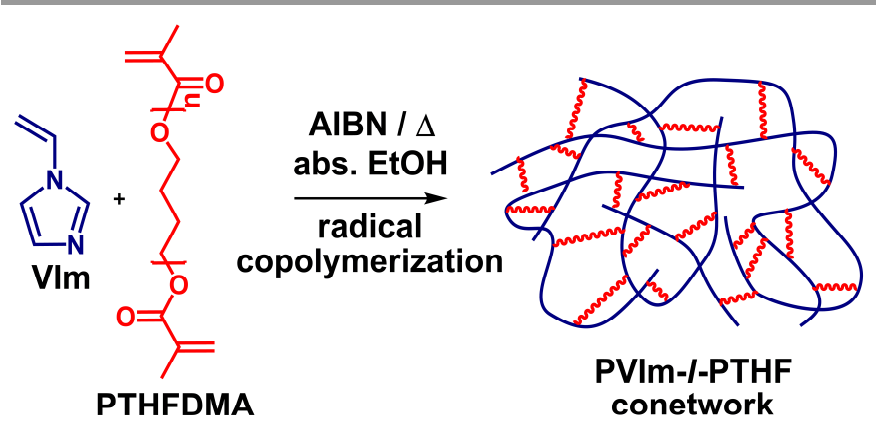

Scheme 1. The formation of poly( $N$-vinylimidazole)-I-poly(tetrahydrofuran) (PVIm-I-PTHF) conetworks by radical copolymerization of $N$-vinylimidazole (VIm) with telechelic poly(tetrahydrofuran) dimethacrylate (PTHFDMA) macromonomer cross-linker.

The thermal behavior of the PVIm- $l$-PTHF conetworks with different contents of various molecular weights of PTHFDMA cross-linkers and that of the pure homopolymers were studied by thermogravimetric analysis (TG) and by thermogravimetrymass spectrometry (TG-MS) coupled technique in inert atmosphere to obtain information on the relation of their structure and thermal behavior as a function of the cross-linker ratio. The TG and the magnified views of the differential mass loss (DTG) curves are shown in Figure 1. The temperature at the maximum rate of decomposition $\left(T_{\mathrm{d}(\max )}\right)$ and the final decomposition temperature $\left(T_{\mathrm{f}}\right)$ are listed in Table 1. This table also includes the char residue $\left(Y_{\mathrm{c}}\right)$ at $500^{\circ} \mathrm{C}$, for the comparability the solvent content of the conetworks were taken into account.

The thermogravimetric curves in Figure 1 indicate that most of the conetworks and the pure PVIm and PTHFDMA homopolymers degrade by a one-stage decomposition. In contrast to the APCNs, the immiscible PVIm/PTHFDMA homopolymer mixtures (blends) show two-stage decomposition as expected, reflecting well the blend composition, and the decomposition temperatures are observed in the range of the pure PVIm and PTHFDMA homopolymers (details of the thermal decomposition of the homopolymers and their blends can be found in the Supporting Information, see Figures S1-S4 and Tables S1 and S2). 

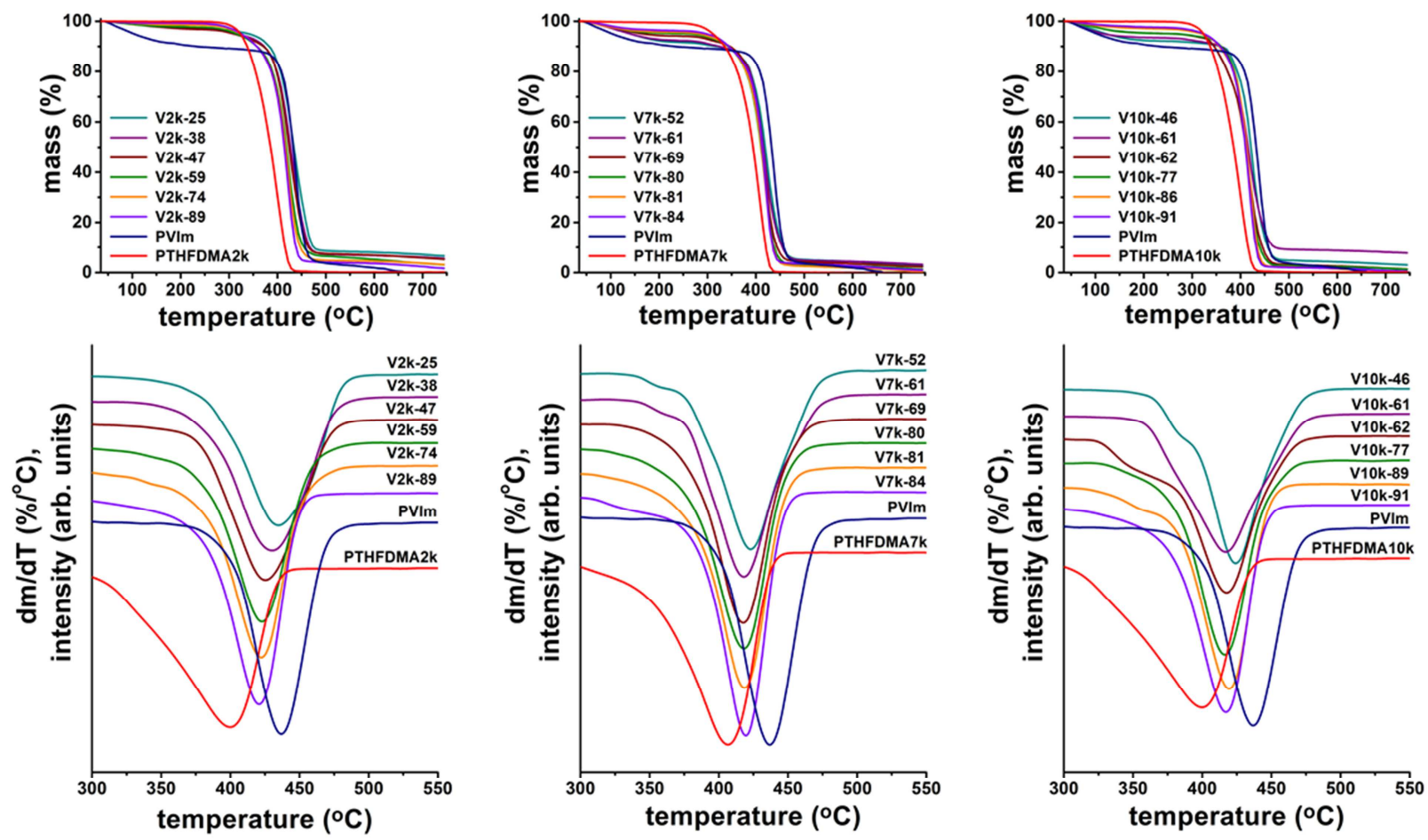

Figure 1. Thermogravimetric (TG) and differential thermogravimetric (DTG) curves of poly(N-vinylimidazole)-I-poly(tetrahydrofuran) (PVIm-I-PTHF) conetworks, poly(N-vinylimidazole) (PVIm) homopolymer and poly(tetrahydrofuran) dimethacrylate (PTHFDMA) cross-linkers.

Table 1. The feed ratios, compositions, $M_{\mathrm{c}}$ values, decomposition temperatures and char yields of poly( $N$-vinylimidazole)- $l$-poly(tetrahydrofuran) (PVIm- $l$ PTHF) conetworks, the poly(tetrahydrofuran) dimethacrylate (PTHFDMA) macromolecular cross-linkers and the poly $(N$-vinylimidazole) (PVIm) homopolymer.

\begin{tabular}{|c|c|c|c|c|c|c|c|}
\hline Sample & $\begin{array}{c}\text { VIm/PTHF feed } \\
\text { ratio (wt\%) }\end{array}$ & $\begin{array}{c}\text { PVIm/PTHF in the } \\
\text { conetwork (wt\%) }\end{array}$ & $\begin{array}{c}M_{\mathrm{c}} \text { of } \\
\text { PVIm }\end{array}$ & $\begin{array}{c}T_{\mathrm{d}(\max )}\left({ }^{\circ} \mathrm{C}\right) \\
\left(\begin{array}{l}\left.{ }^{\circ} \mathrm{C}\right)\end{array}\right.\end{array}$ & $\begin{array}{c}Y_{\mathrm{c}} \\
(\%)\end{array}$ & $\begin{array}{c}Y_{\mathrm{c}}(\mathrm{PVIm}) \\
(\%)\end{array}$ \\
\hline V2k-25 & $80 / 20$ & $75 / 25$ & 3260 & 432 & 488 & 8.6 & 11.8 \\
\hline V2k-38 & $70 / 30$ & $62 / 36$ & 1770 & 430 & 485 & 7.3 & 12.1 \\
\hline V2k-47 & $60 / 40$ & $53 / 47$ & 1220 & 425 & 483 & 7.5 & 14.6 \\
\hline V2k-59 & $50 / 50$ & $41 / 59$ & 750 & 423 & 482 & 6.5 & 16.3 \\
\hline V2k-74 & $40 / 60$ & $26 / 74$ & 380 & 422 & 477 & 4.9 & 19.1 \\
\hline V2k-89 & $30 / 70$ & $11 / 89$ & 130 & 420 & 459 & 4.1 & 37.6 \\
\hline V7k-52 & $80 / 20$ & $48 / 52$ & 3120 & 423 & 487 & 5.1 & 11.6 \\
\hline V7k-61 & $70 / 30$ & $39 / 61$ & 2160 & 420 & 486 & 4.8 & 13.3 \\
\hline V7k-69 & $60 / 40$ & $31 / 69$ & 1520 & 418 & 477 & 4.2 & 14.4 \\
\hline V7k-80 & $50 / 50$ & $20 / 80$ & 850 & 417 & 472 & 3.1 & 16.3 \\
\hline V7k-81 & $40 / 60$ & $19 / 81$ & 790 & 417 & 464 & 3.2 & 13.8 \\
\hline V7k-84 & $30 / 70$ & $16 / 84$ & 650 & 417 & 459 & 2.5 & 22.7 \\
\hline V10k-46 & $80 / 20$ & $54 / 46$ & 5790 & 424 & 487 & 4.8 & 9.6 \\
\hline V10k-61 & $70 / 30$ & $39 / 61$ & 3150 & 418 & 482 & 9.2 & 25.3 \\
\hline V10k-66 & $60 / 40$ & $34 / 66$ & 3020 & 418 & 475 & 3.1 & 9.9 \\
\hline V10k-77 & $50 / 50$ & $23 / 77$ & 1470 & 416 & 472 & 2.7 & 12.3 \\
\hline V10k-86 & $40 / 60$ & $14 / 86$ & 800 & 416 & 463 & 2.2 & 16.2 \\
\hline V10k-91 & $30 / 70$ & $9 / 91$ & 490 & 412 & 457 & 2.0 & 22.8 \\
\hline PVIm & -- & -- & -- & 437 & 487 & 3.7 & 5.6 \\
\hline PTHFDMA2k & -- & -- & -- & 407 & 441 & 0.2 & 0.2 \\
\hline PTHFDMA7k & -- & -- & -- & 403 & 441 & 0.1 & 0.1 \\
\hline PTHFDMA10k & -- & -- & -- & 400 & 442 & 0.2 & 0.2 \\
\hline
\end{tabular}

$T_{\mathrm{d}(\max )}\left({ }^{\circ} \mathrm{C}\right)$ : temperature of maximum rate of weight loss; $T_{\mathrm{f}}\left({ }^{\circ} \mathrm{C}\right)$ : final decomposition temperature; $Y_{\mathrm{c}}(\%)$ : char yield at $500^{\circ} \mathrm{C} ; Y_{\mathrm{c}}(\mathrm{PVIm})(\%)$ : char yield related to PVIm content at $500^{\circ} \mathrm{C}$ 
PTHF in the blends with other endgroups, such as hydroxyl, can also be considered for comparison. However, as shown in Figures S4-S7 (in the Supporting Information), the thermal decomposition products of the methacrylate-telechelic and hydroxyl-telechelic PTHF samples are essentially identical. Thus, PTHDMA is a suitable choice for comparing the thermal decomposition of its PVIm mixtures with that of the PVIm- $l$ PTHF conetworks. The $T_{\mathrm{d}(\max )}$ for the PTHFDMA macromononomers is observed between 400 and $407^{\circ} \mathrm{C}$ (Figure 1 and Table 1). It has to be noted that the $T_{\mathrm{d}(\max )}$ of PTHF with different functional groups varies between 272 and $432^{\circ} \mathrm{C}$ in the literature. ${ }^{14 a-h}$ The thermal stability of the macromolecular PTHFDMA cross-linkers is found not to depend strongly on their molecular weights; in fact $T_{\mathrm{d}(\max )}=407,403$ and $400^{\circ} \mathrm{C}$ for $M_{\mathrm{n}}(\mathrm{PTHF})=2200,6800$, and 10000 , respectively. It is observed that the PTHFDMA has lower thermal stability than PVIm. In other words PVIm is more stable (the early weight loss is due to the elimination of the residual solvents) than the PTHFDMA bis-macromonomers. The decomposition temperature of PVIm is at $440^{\circ} \mathrm{C}\left(T_{\mathrm{d}(\max )}=455^{\circ} \mathrm{C}\right.$ by TG-MS measurement $\left.{ }^{11}\right)$. In the case of conetworks with higher molecular weight PTHFDMA cross-linkers (V7k and V10k series) a broader endothermic peak can be detected in the temperature range between 150 and $250^{\circ} \mathrm{C}$ by DSC, which corresponds to the dehydration of the conetworks, that is to the elimination of strongly retained, physically bound (adsorbed) water from the PVIm hydrophilic polymer part of the conetwork. ${ }^{11}$ Removing the residual solvents by heating at $50^{\circ} \mathrm{C}$ (to avoid any kind of preliminary degradation) under vacuum was not sufficient to completely eliminate the solvents which are responsible for the early weight losses below the decomposition temperatures.

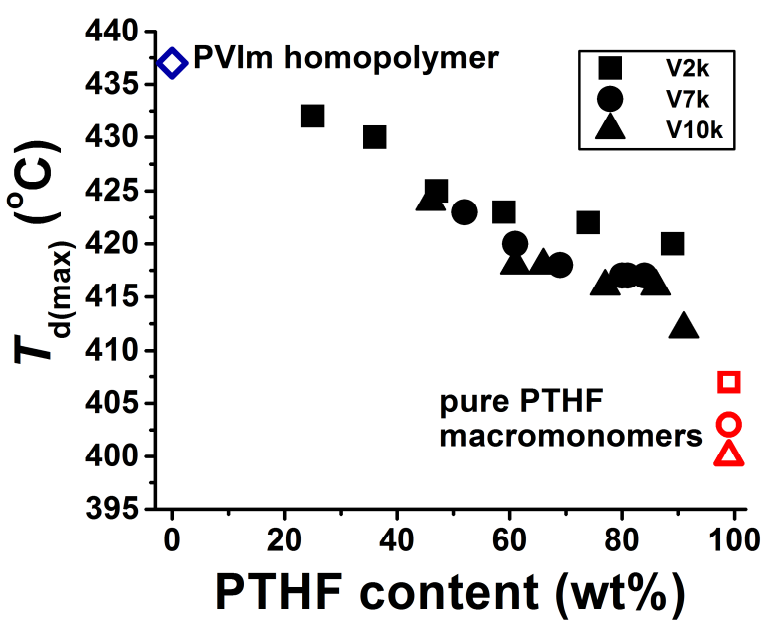

Figure 2. Temperatures of the maximum rate of degradation $\left(T_{\mathrm{d}(\max )}\right)$ as a function of PTHF content in the poly( $N$-vinylimidazole)-I-poly(tetrahydrofuran) (PVIm-I-PTHF) conetworks. The open blue diamond symbol represents the pure $\operatorname{poly}\left(N\right.$-vinylimidazole) $(\mathrm{PVIm})$ homopolymer, while the open square $\left(M_{\mathrm{n}}=2200\right)$, red circle $\left(M_{\mathrm{n}}=6800\right)$ and triangle $\left(M_{\mathrm{n}}=10000\right)$ stand for the $T_{\mathrm{d}(\max )}$ of the poly(tetrahydrofuran) dimethacrylate (PTHFDMA) cross-linkers.
It is also evident from the data in Figure 1 and Table 1 that the major thermal decomposition of the PVIm-l-PTHF conetworks occurs between the decomposition ranges of PTHFDMA and PVIm by overlapping volatilization steps in contrast to expectations in the case of most of the conetworks.

The temperatures of the weight loss with maximum rate of degradation for the conetworks and the pure homopolymers as a function of the PTHF content in the conetworks are shown in Figure 2. As presented in this Figure, the temperatures of the maximal rate of thermal decomposition of the PVIm- $l$-PTHF conetworks fall between that of the two homopolymers, and are shifted to higher values as the relative amount of the PTHF cross-linker decreases. Surprisingly, all the $T_{\mathrm{d}(\max )}$ values fall on the same curve independent of the molecular weight of the PTHFDMA macromolecular cross-linker.

(a)

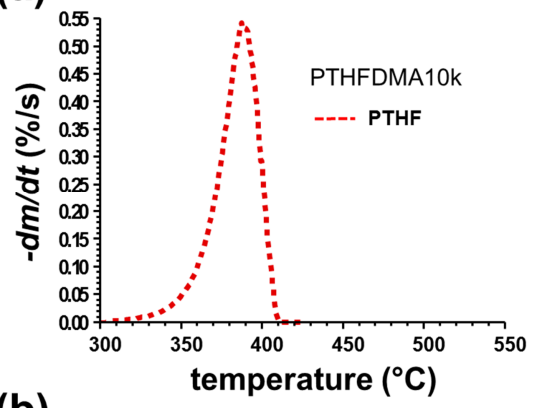

(b)

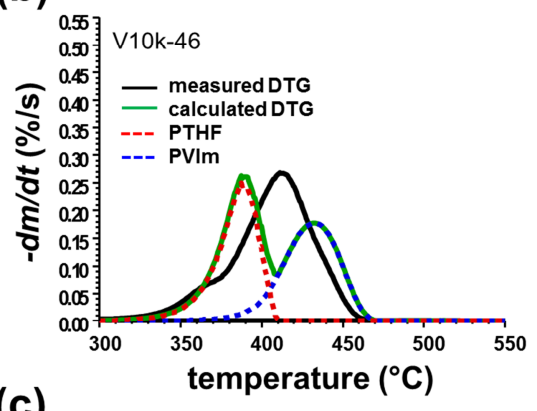

(c)

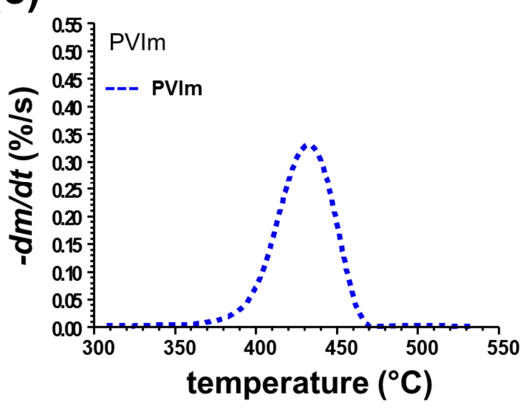

Figure 3. Differential thermogravimetric (DTG) curves of the macromolecular poly(tetrahydrofuran) dimethacrylate cross-linker (PTHFDMA) $\left(M_{n}=10000\right)(a)$, the poly( $N$-vinylimidazole)-I-poly(tetrahydrofuran) (PVIm-I-PTHF) conetwork containing 46 wt\% PTHF (black), the PTHFDMA cross-linker $\left(M_{n}=10000\right)$ (red) and the poly( $N$-vinylimidazole) (PVIm) homopolymer (blue) in 46/54 PTHF/PVIm ratio and the superposition (calculated) of the two homopolymer's DTG curves (green) (b), and the PVIm homopolymer (c). 
It can also be clearly observed in Figure 2 that even a small amount of PVIm in the conetworks leads to a significant increase in the decomposition temperatures. Only 9-16 wt\% PVIm in the conetworks raise the $T_{\mathrm{d}(\max )}$ of PTHF by $12-15^{\circ} \mathrm{C}$. Nevertheless, not only the decomposition temperature but the extent of maximal rate of decomposition of the homopolymer components also varies in the conetworks as shown in Figure 3. The DTG curves in this Figure indicate that the rate of decomposition is higher at the beginning of the weight loss while around the temperature of maximal rate it is slower than calculated by superposition of weight losses of the homopolymer components.

For the better understanding of thermal processes and reactions, the measured and calculated DTG curves of the conetworks are compared (see Figure 3 for the V10k-46 sample). The calculated curves obtained by superposition of the DTG curves of the homopolymers show the expected shape of DTG curves in which no interaction is assumed between the PTHF and PVIm during thermal decomposition. As Figure 3b, Figures S8b-d and Figures S8f-h (in the Supporting Information) show, there are considerable differences between the measured and calculated DTG curves of the PVIm- $l$-PTHF conetworks. On the basis of the calculated DTG curves, distinct two-stage decomposition can be expected for the decomposition of the conetworks if independent pyrolysis of the PVIm and PTHF components occurred. However, the measured curves indicate uniform coinciding decomposition of PVIm and PTHF in the PVIm- $l$-PTHF conetworks. These differences between the measured and calculated DTG curves indicate that strong chemical interactions take place between the components in the conetworks during thermal decomposition. In the conetworks, the major decomposition of PTHF is shifted to higher, while that of the PVIm component to lower temperatures in comparison to that of the corresponding homopolymers. Apparently, the two polymers have considerable influence on each other's decomposition mechanism due to the conetwork structure in the PVIm- $l$-PTHF conetworks.

The data of the TG analysis show that the PTHFDMA macromolecular cross-linker has low char yield (0.1-0.2\%), while the PVIm-l-PTHF conetworks (2.0-9.2\%) and PVIm homopolymer $(3.7 \%)$ have higher, but still low char yields after thermal degradation. Several structural parameters are present in the polymer conetworks, such as the average molecular weights of the hydrophilic PVIm segments between two crosslinking points $\left(M_{\mathrm{c}}\right)$, the composition of the conetworks and the number average molecular weight of the hydrophobic PTHFDMA macromolecular cross-linker. As described above, the PVIm segments have effect of on the thermal behavior of conetworks. Because $M_{\mathrm{c}}$ of PVIm is a characteristic structural parameter, the $T_{\mathrm{d}(\max )}$ values are plotted as a function of $M_{\mathrm{c}}$ (Figure 4). As shown in this Figure, the $T_{\mathrm{d}(\max )}$ linearly increases with $M_{\mathrm{c}}$ within each conetwork series, in which the $M_{\mathrm{n}}$ of the PTHF macromolecular cross-linker is constant. It is evident that at a given $M_{\mathrm{c}}$ the relative order of thermal stability is $\mathrm{V} 2 \mathrm{k}>\mathrm{V} 7 \mathrm{k}>\mathrm{V} 10 \mathrm{k}$ for the PVIm- $l$-PTHF conetworks, that is shorter the PTHFDMA macromolecular cross-linker higher the decomposition temperature of the conetworks. This indicates that the stability improving interaction of the PVIm segments is more efficient for shorter PTHF chains than that for longer ones, on the one hand. On the other hand, it is also clearly seen in Figure 3 that the decomposition temperature of the conetworks lies in between that of the composing PVIm and PTHF homopolymers.

In order to reveal the underlying mechanism of the unexpected thermal stability and decomposition of PVIm- $l$ PTHF conetworks, TG-MS measurements of conetworks with low $\left(M_{\mathrm{n}}=2200\right)$ and high $\left(M_{\mathrm{n}}=10000\right)$ molecular weight cross-linkers were carried out. Figure 5 shows the TG, DTG and the characteristic fragment ion of THF, its oligomers and the molecular ion curves of $1 H$-imidazole and 1vinylimidazole.

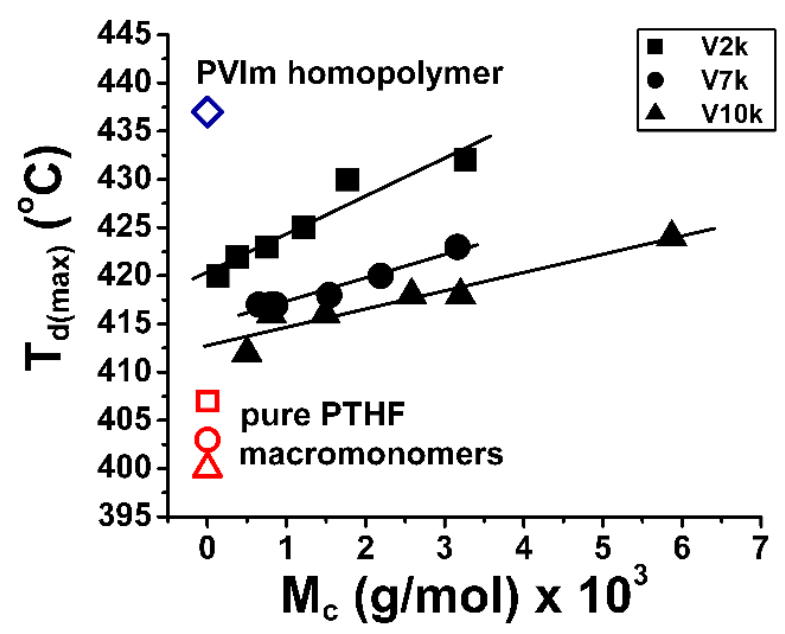

Figure 4. Correlation between the temperature of weight loss at maximum rate of degradation $\left(T_{\mathrm{d}(\max )}\right)$ of the poly( $N$-vinylimidazole)-I-poly(tetrahydrofuran) (PVIm-I-PTHF) conetworks and the average molecular weights of the hydrophilic PVIm segments between two cross-linking points $\left(M_{\mathrm{c}}\right)$. The open blue diamond symbol represents the pure PVIm homopolymer, while the open red square $\left(M_{\mathrm{n}}\right.$ $=2200)$, circle $\left(M_{\mathrm{n}}=6800\right)$ and triangle $\left(M_{\mathrm{n}}=10000\right)$ show the $T_{\mathrm{d}(\max )}$ of the PTHFDMA cross-linkers.

The observed results are interpreted by considering the thermal decomposition properties of PVIm and PTHF. As the TG and DTG curves in Figure 5a show PTHFDMA $\left(M_{\mathrm{n}}=2200\right)$ has relatively low thermal stability. Even in the temperature domain of $200-310^{\circ} \mathrm{C}$ approximately $6 \%$ mass loss can be detected. However, the volatile formation in this temperature range cannot be due to radical scission of the $\mathrm{C}-\mathrm{O}$ bonds. ${ }^{17}$ The main decomposition takes place in one step in the temperature range of $310-425^{\circ} \mathrm{C}$ leading to negligible amount of solid residue. THF and THF oligomers are characteristic thermal decomposition products of PTHF. ${ }^{18}$ The ion curves of $\mathrm{m} / \mathrm{z} 71$ and $\mathrm{m} / \mathrm{z} 72$ were monitored in order to follow the thermal decomposition of PTHF ( $\mathrm{m} / \mathrm{z} 71$ is a characteristic fragment ion of THF oligomers, $\mathrm{m} / \mathrm{z} 72$ is the molecular ion of THF). The maxima of these ion curves and the DTG curve of both 
PTHFDMA samples appear approximately at the same temperature (around $400^{\circ} \mathrm{C}$ ) in Figures 5a and 5e.

Thermal decomposition of the other constituent polymer, that is PVIm, was studied in details recently in our laboratory. ${ }^{11}$ As Figure 5i shows the decomposition of PVIm takes place in the temperature range of $360-480^{\circ} \mathrm{C}$, that is at significantly higher temperature than that of PTHF, and 5\% solid residue remains due to char formation reactions taking place in the temperature range of $500-700^{\circ} \mathrm{C}$. (See Figure S9 in the Supporting Information for the char yields and the shape of the $\mathrm{m} / \mathrm{z} 15 \mathrm{CH}_{3}{ }^{+}$molecular ion curves.) It should be noted that the mass loss up to $200^{\circ} \mathrm{C}$ is due to adsorbed water, moreover further negligible mass loss can be detected until $340^{\circ} \mathrm{C}$ which is caused by the liberation of included acetone. ${ }^{11}$

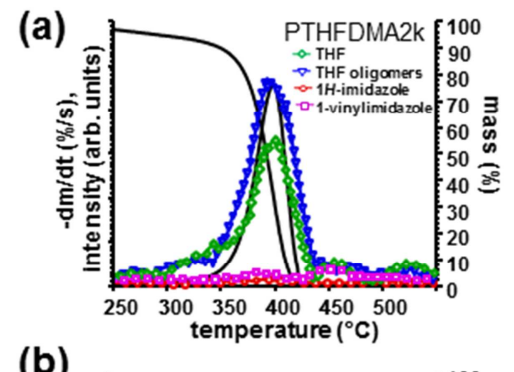

(b)
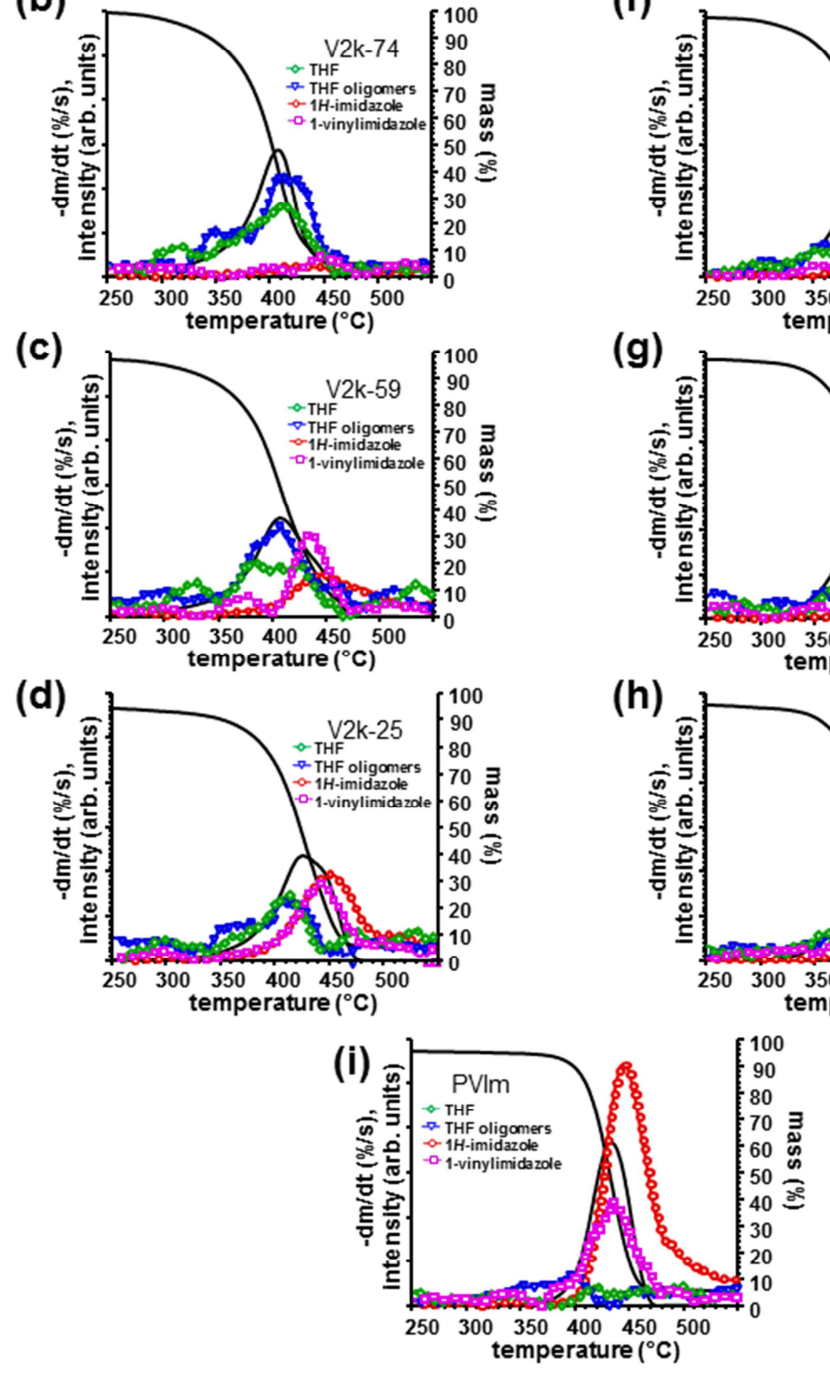

(f)
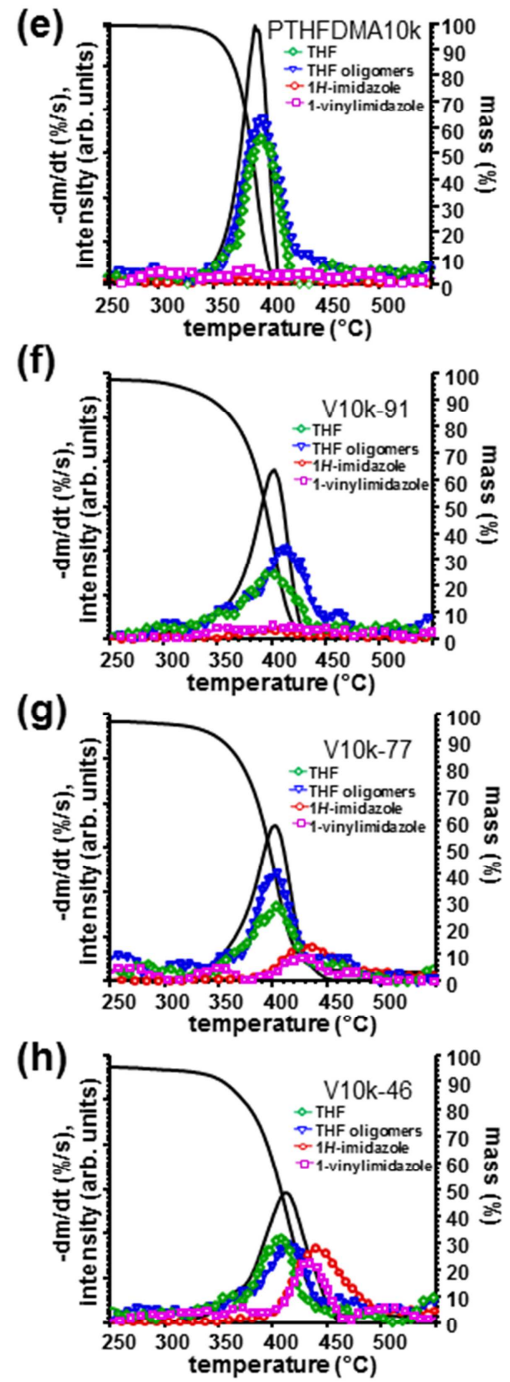

Figure 5. Thermogravimetric (TG), differential thermogravimetric (DTG), and TG-MS molecular ion curves of PTHF $\left(M_{\mathrm{n}}=2200\right)(\mathrm{a})$, poly $(N$-vinylimidazole) -1 poly(tetrahydrofuran) (PVIm-I-PTHF) conetworks containing 74 wt\% (b), $59 w t \%$ (c) 25 wt $\%$ (d) of PTHFDMA cross-linker $\left(M_{\mathrm{n}}=2200\right)$, PTHFDMA $\left(M_{\mathrm{n}}=10000\right)(\mathrm{e})$ PVIm-I-PTHF conetworks containing 91 wt\% (f), 77 wt\% (g) 46 wt\% (h) of PTHF cross-linker $\left(M_{n}=10000\right)$, and PVIm homopolymer (i). Mass loss and DTG curves: solid lines; TG-MS characteristic fragment ion of THF (m/z 72): green, its oligomers (m/z 71): blue; molecular ion curve of $1 \mathrm{H}$-imidazole ( $\mathrm{m} / \mathrm{z} 68)$ : red; molecular ion curve of 1-vinylimidazole ( $\mathrm{m} / \mathrm{z}$ 94): magenta. 
The TG-MS ion profiles at m/z 68 and m/z 94 indicate the two most typical products of PVIm, namely $1 H$-imidazole and 1 vinylimidazole, respectively. The maximum of the ion curve of 1-vinylimidazole appears at $430^{\circ} \mathrm{C}$, that of $1 \mathrm{H}$-imidazole at $450^{\circ} \mathrm{C}$, while the DTG maximum is at $440^{\circ} \mathrm{C}$ in Figure $5 \mathrm{i}$.

The ion curves of m/z 71 and m/z 72 in Figure 5 confirm that the thermal decomposition of the PTHF polyether chain segments is responsible for the mass loss in the lower temperature domain, while in the higher temperature range the PVIm chains decompose $(\mathrm{m} / \mathrm{z} 68$ and $\mathrm{m} / \mathrm{z} 94)$. The maxima of the monitored ion profiles appear at lower and higher temperatures for PVIm and PTHF, respectively, in all the conetworks as compared to that of the corresponding homopolymers. Nevertheless, the shape of the ion profiles attributed to THF oligomers are varying in the temperature range from 270 to $340^{\circ} \mathrm{C}$, which corresponds to the beginning of decomposition with increased weight loss in case of the conetworks. The ratio of the characteristic ions at $\mathrm{m} / \mathrm{z} 71$ and $\mathrm{m} / \mathrm{z} 72$ differs from that observed in the range between 360$440^{\circ} \mathrm{C}$ indicating the occurrence of another reaction at a lower temperature preceding the radical decomposition of the PTHF cross-linker polyether. We may suppose that this additional reaction is related to the cross-linking units, as its importance seems to be the highest in the case of conetworks having the shortest VIm segments between the cross-linking units, namely the highest frequency of them along the PVIm chains. Since the cross-linking between the PTHFDMA macromonomer and PVIm consists of an ester bond, it decomposes most probably by cis-elimination, which reaction is typically occurring in aliphatic polyesters with methacrylate monomer units in the temperature range from 250 to $300^{\circ} \mathrm{C} .{ }^{19,20}$ Such cis-elimination reaction of the cross-linking unit results in a vinyl terminating group in the PTHF maromonomer and in a methacrylic acid monomeric unit within the PVIm segment. This reaction disconnects the cross-linkers from the PVIm chain, namely abolishes the conetwork structure, but in itself does not produce volatile compounds. Therefore, about the reaction taking place during decomposition of the PVIm- $l$-PTHF conetworks in this starting period, we may assume that it is not a radical process of the PTHF. At higher temperatures, the protonated imidazole groups being firmly attached to the PVIm chain (Scheme 2) cannot be eliminated resulting in suppressed formation of $1 \mathrm{H}$ imidazole from the conetworks. It has to be noted that this ciselimination mechanism also explains recent findings by Patrickios et al. $^{21}$ according to which poly(2-(1-imidazolyl) ethyl methacrylate) decomposes to poly(methacrylic acid) and 1-vinylimidazole under inert atmosphere at temperature as low as $200^{\circ} \mathrm{C}$.

The temperature at the molecular ion curve maximum of $1 H$-imidazole and 1-vinylimidazole $(\mathrm{m} / \mathrm{z} 68$ and $\mathrm{m} / \mathrm{z} 94$, respectively) does not alter notably for PVIm in the conetworks, however the relative ion intensities of $\mathrm{m} / \mathrm{z} 68$ and $\mathrm{m} / \mathrm{z} 94$ significantly changes. As the ion curves of PVIm decomposition show (Figure 5i), the amount of $1 \mathrm{H}$-imidazole is exceedingly greater than that of 1-vinylimidazole from the homopolymer. The ratio of ion intensities characteristic for the two main products of PVIm is noticeably changed in the conetworks indicating the increased importance of the free radical depolymerization of PVIm in the conetworks. We may suppose that some of the macroradicals formed by the homolytic scission of the PTHF cross-linkers which are in molecular vicinity with the PVIm segments initiate its decomposition by abstracting tertiary hydrogen from the PVIm chains as shown in Scheme 2. This results in considerably increasing VIm formation. At the same time, hydrogen abstraction by PTHF macroradicals decreases the depolymerization rate of PTHF leading to increased thermal stability of these macromolecular segments in the conetworks.

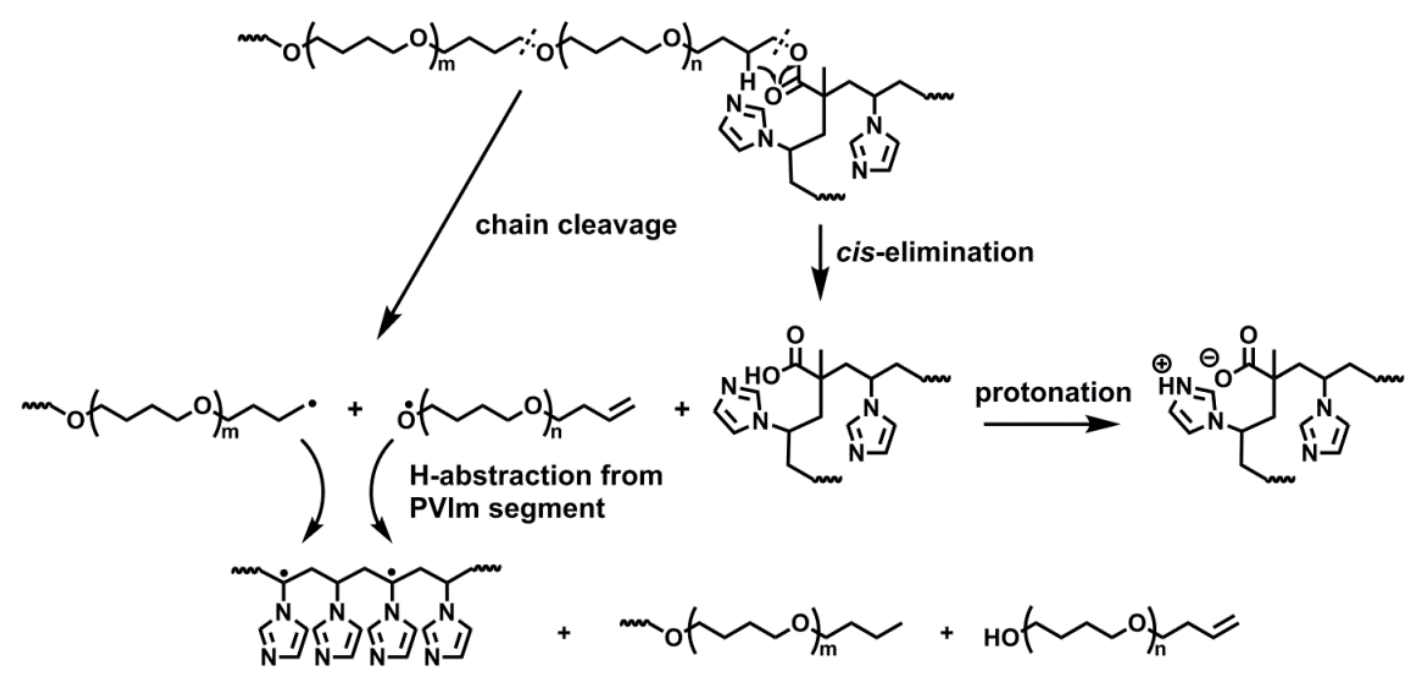

Scheme 2. The mechanism of thermal decomposition of poly( $N$-vinylimidazole)-I-poly(tetrahydrofuran) (PVIm- - -PTHF) conetworks via simultaneous cis-elimination of methacrylate ester groups, homolytic chain scission of PTHF chains and hydrogen abstraction from the PVIm segments. 
The extent of side group scission to form PVIm to from $1 \mathrm{H}$ imidazole is depressed, partly because an important part of this conetwork component is consumed by depolymerization that occurs at a slightly lower temperature than side group elimination, partly due to the ionic effect of the methacrylic acid monomeric unit formed by the decomposition of the crosslink shown in Scheme 2. The ion intensity of the $1 H$-imidazole evolved from the conetworks noticeably decreases with decreasing ratio of PVIm component, indicating that the side group cleavage is more and more hindered (compare Figures $5 \mathrm{c}-\mathrm{d})$. In the conetworks containing shorter VIm segments than $500 \mathrm{D}$, ion intensities of $1 \mathrm{H}$-imidazole and 1 -vinylimidazole drops to noise level.

Char formation is enhanced in all conetworks (see Table 1) leading to relatively large amounts of solid residue. Further TGMS measurements have confirmed that the char formation is due primarily to the presence of PVIm segments. Figure 6 shows that the amount of char related to PVIm content increases monotonously as the average molecular weight of the hydrophilic PVIm segments between two cross-linking points $\left(M_{\mathrm{c}}\right)$ decreases. This correlation is independent of the molecular weight of the PTHFDMA cross-linker. This observation may be explained by the hindering action of the scission of the conetwork at the methacrylate ester groups (see Scheme 2) on the elimination of $1 H$-imidazole from the PVIm chains. In this reaction, the methacrylate units are added to both ends of the PVIm fragments, and thus becoming in this way the more carbonizable the smaller is the molecular mass of the PVIm segments $\left(M_{\mathrm{c}}\right)$. Ion curves of $\mathrm{m} / \mathrm{z} 15$ and $\mathrm{m} / \mathrm{z} 2$ confirm that in the temperature range between 500 to $700^{\circ} \mathrm{C}$ char formation takes place indicated by the evolution of methane and hydrogen during carbonization (details can be found in the Supporting Information, see Figure S9).

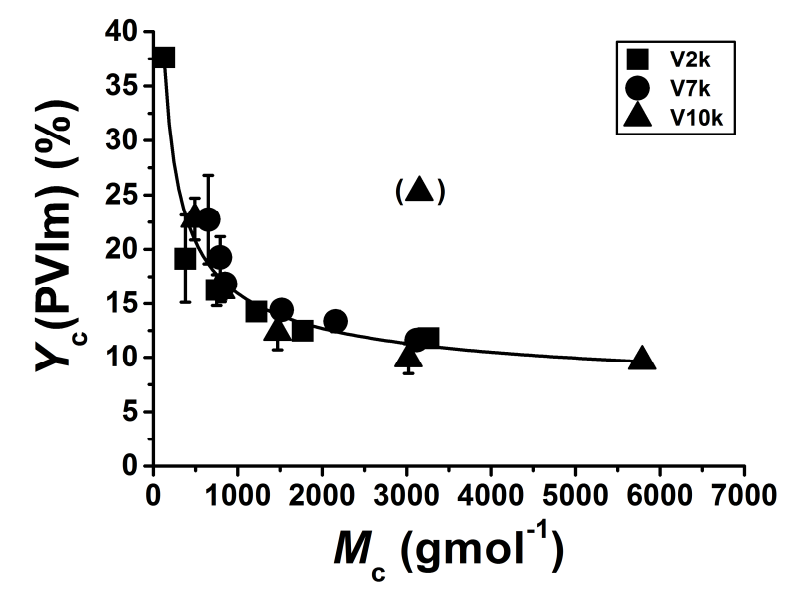

Figure 6. The amount of char related to poly(N-vinylimidazole) (PVIm) content $\left(Y_{c}(P V I m)\right)$ of the poly(N-vinylimidazole)-I-poly(tetrahydrofuran) (PVIm-I-PTHF) conetworks as a function of the average molecular weight of PVIm segments between two cross-linking points $\left(M_{c}\right)$.

\section{Conclusions}

Thermogravimetric (TG) and TG-mass spectrometry (TGMS) analyses of polymer conetworks, a class of chemically forced blends, based on poly ( $N$-vinylimidazole) (PVIm) crosslinked by polytetrahydrofuran dimethacrylate (PTHFDMA) macromolecular cross-linkers of various molecular weights indicate that the thermal decomposition of the conetworks occurs in the temperature range between 250 and $500^{\circ} \mathrm{C}$ resulting in wide DTG peak of volatilization leaving some percent of char. The main thermal decomposition of the PVIm$l$-PTHF conetworks, which can be viewed as chemically forced blends between immiscible polymer chains, occurs between that of the two components indicating that the two chains in close molecular vicinity in these macromolecular assemblies influence each other's degradation routes. The temperature of the highest rate of decomposition $T_{\mathrm{d}(\max )}$ of the conetworks was found between that of the PVIm and PTHFDMA homopolymers, and a universal correlation was found between $T_{\mathrm{d}(\max )}$ and the composition of the conetworks. As the TG-MS measurements revealed, the main decomposition of the PTHF cross-linker chains take place at higher while the PVIm chains decompose at lower temperatures in the conetworks than that of the corresponding homopolymers. This unexpected thermal decomposition behavior can be explained by the occurrence of simultaneous interconnected series of reactions between the decomposing polymer components. The ester group of the methylacrylate in the PTHF cross-linker chain can be considered as a thermally labile point of the conetwork decomposing by cis-elimination. Although this reaction abolishes the network structure, it has no volatile products. This cis-elimination mechanism also provides explanation for the results of a recent report ${ }^{21}$ according to which poly(methacrylic acid) and 1-vinylimidazole are formed by thermal treatment of poly(2-(1-imidazolyl) ethyl methacrylate).Nevertheless, below the onset temperature of homolytic scission and radical decomposition of PTHF in the conetworks, an additional reaction takes place decomposing a not negligible part of the macromonomers. This reaction is negligible in the case of loose network structures with low frequency of cross-linking units along the PVIm chain. The maxima of the formation of THF and volatile oligomers by the main radical decomposition of PTHF macromonomer are at somewhat higher temperatures in the conetworks than that of the pure macromonomers. This range coincides in large part with the first part of PVIm decay temperature range, thus some PTHF radicals can initiate the free radical decomposition of the PVIm segments enhancing the monomer production at the expense of side group scission, that is, the more important main thermal decomposition reaction of the PVIm homopolymer. In addition, crotonic acid units formed by cis-elimination of the ester groups of the cross-links are also hindering side group cleavage, and promoting char formation from the PVIm components In overall, these unique interconnected reaction sequences lead to the observed uniform decomposition of the PVIm- $l$-PTHF conetworks at reasonably high temperatures, which might be utilized in several advanced 
applications. These new results may contribute to the better understanding and utilization of bi- and multicomponent polymer systems, such as blends, copolymers, networks, composites and hybrids from the nanoscale to macroscopic polymeric materials, and from polyionic liquids to fuel cells, nanocatalysis etc.

\section{Experimental}

Materials. $N$-vinylimidazole (VIm, Aldrich) was vacuum distilled from $\mathrm{CaH} 2\left(95 \%\right.$, Aldrich) at $72{ }^{\circ} \mathrm{C}$, and kept under nitrogen until used. 2,2'-Azobis(2-methylpropionitrile) (AIBN, Aldrich) was used as initiator and recrystallized from methanol before use. Freshly distilled absolute ethanol (EtOH, Molar Chemicals Ltd.) and benzene (Bz, Spektrum 3D) were used as solvents for the conetwork syntheses and VIm homopolymerization, respectively. Methanol (MeOH, Spectrum 3D) and tetrahydrofuran (THF, Spektrum 3D) were used as received. Methacrylate-telechelic PTHF (PTHFDMA) cross-linkers were synthesized in our laboratory as reported previously. ${ }^{12 \mathrm{e}, \mathrm{f}}$

Preparation of $\operatorname{poly}(N$-vinylimidazole) (PVIm) homopolymer. The PVIm homopolymer as "standard" for the thermal measurements was synthesized by radical polymerization of $N$-vinylimidazole (VIm) in benzene with AIBN thermal initiator as it was described by us previously. ${ }^{12 \mathrm{f}}$

Synthesis of poly( $N$-vinylimidazole)- $l$-poly(tetrahydrofuran) (PVIm-l-PTHF) conetworks. The PVIm- $l$-PTHF APCN samples were prepared by free radical copolymerization of VIm and PTHFDMA as cross-linker with AIBN as initiator as it is shown in Scheme 1. Conetworks were synthesized according the previously reported $\operatorname{method}^{12 \mathrm{f}, 18}$ with PTHF bismacromonomer cross-linkers of various molecular weights $\left(M_{\mathrm{n}}(\mathrm{PTHFDMA})=2200,6800\right.$, and 10,000 for the V2k, V7k, and V10k sample series, respectively). In brief, for the synthesis of the conetwork samples, the desired amounts of the PTHF cross-linking agent and VIm comonomer, initiator stock solution and ethanol as common solvent for all components were measured into glass vials. The reaction mixtures were homogenized and the oxygen was removed by nitrogen purging. The solutions were poured into teflon molds in an AtmosBag ${ }^{\text {TM }}$ (Sigma Aldrich) under nitrogen atmosphere. Then the molds were closed under nitrogen and kept in an oven at $65^{\circ} \mathrm{C}$ for a period of 3 days. Subsequently, the molds were cooled to room temperature, and the solvent was evaporated, followed by drying the conetworks under vacuum overnight. The resulting cross-linked polymers were extracted with tetrahydrofuran (THF) and methanol $(\mathrm{MeOH})$ for one week with both solvents. Finally, the extracted conetworks were dried to constant weight under vacuum at $50^{\circ} \mathrm{C}$ (and not at higher temperatures in order to avoid any predecomposition).

Preparation of homopolymer blends based on poly( $N$-vinylimidazole)/poly(tetrahydrofuran) (PVIm/PTHF). For the preparation of blends (mixtures) of PVIm and PTHFDMA homopolymers, first both polymers were dissolved in EtOH cosolvent separately. Then, the solutions were mixed to obtain mixtures with different PVIm/PTHFDMA weight ratios (25:75, 50:50 and 75:25) with moderate shaking for few hours at room temperature. The prepared mixtures were poured into a glass mould and the solvent was removed by evaporation. Thin films were formed, which were dried under vacuum overnight to remove the residual solvent. PTHDMA was chosen for the polyether component of equivalent blends with similar chemical composition to that of the corresponding PVIm- $l$ PTHF conetworks for making comparison between the conetworks and the immiscible PVIm/PTHF mixtures after being ascertained on the similarity of the thermal decomposition reactions of PTHFDMA and hydroxyl-telechelic PTHF (PTHFDOH) (see Figs. S5-S7 in the Supporting Information).

Methods. ${ }^{1} \mathrm{H}$ NMR spectroscopy was used to obtain the chemical composition and the purity of the monomer and polymers used in this research. 1H NMR spectra were obtained on a Mercury Plus Varian VRX-200 spectrometer operating at $1 \mathrm{H}$ frequency of $200 \mathrm{MHz}$. Samples were dissolved in appropriate deuterated solvents (deuterated chloroform and deuterium oxide). In the case of deuterated chloroform, tetramethylsilane (TMS) at 0 ppm was used as internal reference for ${ }^{1} \mathrm{H}$ NMR.

Gel permeation chromatography (GPC) measurements were made with an instrument composed of a Waters 515HPLC pump and Polymer Laboratories Mixed C type column set with three columns. Freshly distilled THF was used as eluent with $1.0 \mathrm{mLmin}-1$ elution rate, and the detection was carried out by a dual RI and viscosity detector (Viscotek Dual 200). Molecular weight averages and molecular weight distributions (MWD) were calculated by the use of universal calibration made with narrow MWD polystyrene standards in the range of 104 to $3 \times 10^{6} \mathrm{~g} \mathrm{~mol}^{-1}$.

The composition of the conetworks was determined by elemental analysis with a Heraeus CHN-O-RAPID instrument. The chemical compositions were calculated from the atomic percentages of carbon, nitrogen and hydrogen.

Annealed PVIm- $l$-PTHF APCNs and neat PVIm and PTHFDMA homopolymers were investigated by thermogravimetric analysis (TG) with a Mettler TG50 instrument to determine the thermal stability and decomposition behavior of the conetworks. The decomposition temperature $\left(T_{\mathrm{d}(\max )}\right)$ of the polymers was assigned to the temperature of the maximum rate of weight loss. Programmed heating from $35^{\circ} \mathrm{C}$ to $750^{\circ} \mathrm{C}$ was used for $\mathrm{TG}$ analysis with $10^{\circ} \mathrm{C} / \mathrm{min}$ heating rate under nitrogen atmosphere.

The thermogravimetry-mass spectrometry (TG-MS) instrument was built from a Perkin-Elmer TGS-2 thermobalance and a Hiden HAL 3F/PIC mass spectrometer connected to a computer. For the examination of thermal stability and decomposition of the polymers, $0.5 \mathrm{mg}$ polymer was placed into the platinum sample pan. The sample was heated at $10^{\circ} \mathrm{C} \min ^{-1}$ up to $800^{\circ} \mathrm{C}$ in a flowing argon atmosphere. The flowing rate of argon was $140 \mathrm{ml} \mathrm{min}^{-1}$. A portion of the volatile products was introduced into the ion source of the mass spectrometer through a glass lined metal 
capillary held at $300^{\circ} \mathrm{C}$. The quadrupole mass spectrometer was operated at $70 \mathrm{eV}$ electron energy. The ion intensities were normalized to the sample mass and to the intensity of the ${ }^{38} \mathrm{Ar}$ isotope of the carrier gas.

\section{Acknowledgements}

The authors are grateful for the elemental, GPC and TG analyses to Dr. Hedvig Medzihradszky-Schweiger, Dr. Márta Szesztay, Mrs. Erzsébet Tyroler and Ms. Judit Szauer, respectively. Partial support of this research by the Hungarian Scientific Research Fund (OTKA K81592) and the National Development Agency (Grant No. KTIA-AIK-12-1-2012-0014) is also acknowledged. János Bozi acknowledges the Postdoctoral Scholarship of the Hungarian Academy of Sciences.

\section{Notes and references}

${ }^{a}$ Polymer Chemistry Group, Institute of Materials and Environmental Chemistry, Research Centre for Natural Sciences, Hungarian Academy of Sciences, Magyar tudósok körútja 2, H-1117 Budapest, Hungary;

${ }^{\mathrm{b}}$ Renewable and Clean Energy Group, Institute of Materials and Environmental Chemistry, Research Centre for Natural Sciences, Hungarian Academy of Sciences, Magyar tudósok körútja 2, H-1117 Budapest, Hungary.

$\dagger$ Electronic Supplementary Information (ESI) available: [details of PVIm/PTHF blends, weight ratios, TG results; measured and calculated DTG curves of the PVIm- $l$-PTHF conetworks; char formation of PVIm- $l$ PTHF APCNs, PVIm and PTHF components; TG, TG-MS, measured and calculated DTG curves and Pyrolysis-GC/MS results of PVIm/PTHF blends]. See DOI: 10.1039/b000000x/

1 (a) Y. S. Guan, H. T. Pu, M. Jin, Z. H. Chang and D. C. Wan, Fuel Cells 2010, 10, 973; (b) Y. S. Guan, H. T. Pu, H. Y. Pan, Z. H. Chang, and M. Jin, Polymer 2010, 51, 5473; (c) A. H. Tian, J.-Y. Kim, J. Y. Shi and K. J. Kim, Power Sources 2008, 183, 1; (d) K. Yin, Z. Zhang, L. Yang and S. I. Hirano, J. Power Sources 2014, 258, 150; (e) H. I. Unal, O. Erol and O. Y. Gumus, Colloids Surf. A: Physicochem. Eng. Aspects, 2014, 442, 132.

2 (a) J. Tu, J. Zhou, C. F. Wang, Q. A. Zhang, and S. Chen, J. Polym. Sci., Part A: Polym. Chem. 2010, 48, 4005; (b) H. Bessbousse, T. Rhlalou, J. F. Verchere and L. Lebrun, J. Chem. Eng. 2010, 164, 37; (c) Z. Ajji and A. M. Ali, J. Hazard. Mater. 2010, 173, 71; (d) F. Özmen, P. A. Kavlaki and O. Güven, J. Appl. Polym. Sci. 2011, 119, 613; (e) H. El-Hamshary, M. M. Fouda, M. Moydeen and S. S., AlDeyab, Int. J. Biol. Macromol. 2014, 66, 289; (f) L. Ranada, M. Akbulut, L. Abad and O. Güven, Rad. Phys. Chem. 2014, 94, 93; (g) S. Yuan, Q. Deng, G. Fang, J. Wu, W. Li and S. Wang, J. Chromat. B. 2014, 960, 239.

3 (a) I. P. Beletskaya, E. A. Tarasenko, A. R. Khokhlov and V. S. Tyurin, Russ. J. Org. Chem. 2010, 46, 461; (b) I. P. Beletskaya, A. V. Selivanova, V. S. Tyurin, V. V. Matveev and A. R. Khokhlov, Russ. J. Org. Chem. 2010, 46, 157; (c) B. Ö. Öztürk, B. Sariaslan, N. P. Bayramgil and S. K. Sehitoglu, Appl. Catal. A: General, 2014, 483, 19; (d) A. V. Selivanova, V. S. Tyurin and I. P. Beletskaya, ChemPlusChem, 2014, 79, 1278; (e) Y. Zhou, M. Zhu and S. Li, J. Mater. Chem. A. 2014, 2, 6834; (f) Y. Han, X. Yuan, M. Zhu, S. Li,
M. J. Whitcombe and S. A. Piletsky, Adv. Funct. Mater. 2014, 24, 4996.

4 S. J. Yuan, S. O. Pehkonen, B. Liang, Y. P. Ting, K. G. Neoh and E. T. Kang, Corros. Sci. 2010, 52, 1958.

5 J. Li, H. F. Han, Q. Wang, X. Liu and S. X. Jiang, J. Sep. Sci. 2010, 33, 2804.

6 M. Schubert and M. A. Glomb, J. Agric. Food Chem. 2010, 58, 8300.

7 S. Isikli, S. Tuncagil, A. Bozkurt and L. Toppare, J. Macromol. Sci., Pure Appl. Chem. 2010, 47, 639.

8 (a) S. Asayama, T. Hakamatani and H. Kawakami, Bioconjugate Chem. 2010, 21, 646; (b) J. E. Ihm, K. O. Han, C. S. Hwang, J. H. Kang, K. D. Ahn, I. K. Han, D. K. Han, J. A. Hubbell and C. S. Cho, Acta Biomater. 2005, 1, 165.

9 K. Shalini, P. S. Sharma and N. Kumar, Der Chemica Sinica 2010, 1, 36.

10 (a) L. Peters, M.-F. Tepedino, T. Haas, F. W. Heineman, M. Wolf and N. Burzlaff, Inorg. Chim. Acta, 2011, 374, 392; (b) L. Cheng, K. G. Abhilash and R. Breslow, Proc. Natl. Acad. Sci. U. S. A., 2012, 109, 12884.

11 Cs. Fodor, J. Bozi, M. Blazsó and B. Iván, Macromolecules 2012, 45, 8953.

12 (a) P. Dreyfuss, In Handbook of Elastomers; A. K. Bhowmick, H. Stephens, Eds.; Marcel Dekker, Inc, New York, NY, 2001; pp ; (b) L. Jong and R. S. Stein, Macromolecules 1991, 24, 2323; (c) A. Hartwig and M. Sebald, Eur. Polym. J. 2003, 39, 1975; (d) A. Gadkari, J. P. Kennedy, M. M. Kory and D. L. Ely, Polym. Bull. 1989, 22, 25; (e) Cs. Fodor and B. Iván, J. Polym. Sci., Part A: Polym. Chem. 2011, 49, 4729; (f) Cs. Fodor, G. Kali and B. Iván, Macromolecules, 2011, 44, 4496; (g) A. Domján, Cs. Fodor, Sz. Kovács, T. Marek, B. Iván and K. Süvegh, Macromolecules, 2012, 45, 7557; (h) Cs. Fodor, A. Domján and B. Iván, Polym. Chem. 2013, 4, 3714.

13 (a) P. Dubois, O. Coulembier and J-M. Raquez, Handbook of RingOpening Polymerization, Wiley-VCH, Weinheim, 2009, p 144; (b) G. Caroli and K. Loos, Macromol. Chem. Phys. 2013, 214, 2602.

14 (a) T. C. Chang, K. H. Wu, H. B. Chen, S. Y. Ho and Y. S. Chiu, J. Polym. Sci., Part A: Polym. Chem. 1996, 34, 3337; (b) L. RuedaLarraz, B. F. d'Arlas, A. Tercjak, A. Ribes, A. Mondragon and A. Eceiza, Eur. Polym. J. 2009, 45, 2096; (c) E. Ünür, L. Toppare, Y. Yagci and F. Yilmaz, Mater. Chem. Phys. 2005, 91, 261; (d) L. Costa, M. P. Luda, G. G. Cameron and M. Y. Qureshi, Polym. Degrad. Stab. 2000, 67, 527; (e) E. Inoue, M. Tsuchiya, K. Isimaru and T. Kojima, J. Therm. Anal. Calorim. 2002, 70, 747; (f) T. Kojima, M. Tsuchiya and K. Tago, J. Therm. Anal. 1997, 49, 149; (g) B. Grass and J. C. Galin Macromolecules 1995, 25, 7035; (h) S. Maier, T. Loontjens, B. Scholtens and R. Mülhaupt Macromolecules, 2003, 36, 4727; (i) C. Özdilek, J. Hacaloglu, L. Toppare and Y. Yagci, Synth. Met. 2004, 140, 69; (j) M. A. Tasdelen, W. Van Camp, E. Goethals, P. Dubois, F. Du Prez and Y. Yagci, Macromolecules 2008, 41, 6035; (k) Y. Wang and E. J. Goethals, Macromolecules 2000, 33, 808; (1) D. Filip, C. I. Simionescu and D. Macocinschi, Thermochim. Acta 2003, 395, 217; (m) M. Kohga and K. Okamoto, Combust. Flame 2011, 158, 573; (n) W. Lequieu, F. E. Du Prez, Polymer 2004, 45, 749-757. (o) O. Akbulut, I. Taniguchi, S. Kumar, Y. Shao-Horn and A. M. Mayes, Electrochim. Acta 2007, 52, 1983; (p) S. Ghosh, D. Khastgir, A. K. Bhowmick and P. G. Mukunda, Polym. Degrad. Stab. 2000, 67, 427;. (q) A. Hartwig and M. Sebald, 
Eur. Polym. J. 2003, 39, 1975; (r) T. Hövetborn, M. Hölscher, H. Keul and H. Höcker, Rev. Roum. Chim. 2006, 51, 781.

15 (a) C. S. Patrickios and T. K. Curr. Op. Coll. Int. Sci., 2003, 8, 76; (b) G. Erdődi and J. P. Kennedy, Prog. Polym. Sci. 2006, 31, 1; (c) L. Mespouille, J. L. Hedrick and P. Dubois, Soft Matter 2009, 5, 4878; (d) J. Xu, M. Qiu, B. Ma and C. He, ACS Appl. Mater. Interfaces, 2014, 6, 15283; (e) C. Zhou, S. Qian, A. Zhang, L. Xu, J. Zhu, Z. Cheng and G. D. Fu, RSC Advances, 2014, 4, 8144; (f) M. Achilleos, M. Demetriou, O. Marinica, L. Vekas and T. Krasia-Christoforou, Polym. Chem., 2014, 5, 4365; (g) V. Stoyneva, D. Momekova, B. Kostova and P. Petrov, Carbohydrate Polym., 2014, 99, 825; (h) J. Tobis and J. C. Tiller, Biotechnol. Letters, 2014, 36, 1661; (i) G. Kali, Sz. Vavra, K. László and B. Iván, Macromolecules, 2013, 46, 5337; (j) L. Shi, P. Xie, Z. Li, Y. Wu and J. Deng, Macromol. Chem. Phys., 2013, 214, 1375; (k) Á. Némethy, K. Solti, L. Kiss, B. Gyarmati, M. A. Deli, E. Csányi and A. Szilágyi, Eur. Polym. J., 2013, 49, 2392; (1) Z. Wei, J. H. Yang, X. J. Du, F. Xu, M. Zrinyi, Y. Osada, F. Li and Y. M. Chen, Macromol. Rapid Commun., 2013, 34, 1464; (m) N. Ghasdian, E. Church, A. P. Cottam, K. Hornsby, M. Y. Leung and T. K. Georgiou, RSC Advances, 2013, 3, 19070; (n) C. Krumm, S. Konieczny, G. J. Dropalla, M. Milbra and J. C. Tiller, Macromolecules, 2013, 46, 3234; (o) X. Fan, M. Wang, D. Yuan and C. He, Langmuir, 2013, 29, 14307; (p) Y. Yuan, A. K. Zhang, J. Ling, L. H. Yin, Y. Chen and G. D. Fu, Soft Matter, 2013, 9, 6309; (q) J. Cui, M. Lackey, G. N. Tew and A. J. Crosby, Macromolecules, 2012, 45, 6104; (r) C. N. Walker, C. Versek, M. Tuominen and G. N. Tew, ACS Macro Lett., 2012, 1, 737.

16 (a) J. Scherble, R. Thomann, B. Iván and R. Mülhaupt, J. Polym. Sci., Part B: Polym. Phys. 2001, 39, 1429; (b) B. Iván, K. Almdal, K. Mortensen, I. Johannsen and J. Kops, Macromolecules 2001, 34, 1579; (d) A. Domján, G. Erdődi, M. Wilhelm, M. Neidhöfer, K. Landfester, B. Iván and H. W. Speiss, Macromolecules 2003, 36, 9107; (e) B. Iván, M. Haraszti, G. Erdődi, J. Scherble, R. Thomann and R. Mülhaupt, Macromol. Symp. 2005, 227, 265; (f) N. Bruns, J. Scherble, L. Hartmann, R. Thomann, B. Iván, R. Mülhaupt and J. C. Tiller, Macromolecules 2005, 38, 2431; (g) J. Tobis, Y. Thomann and J. C. Tiller, Polymer 2010, 51, 35; (h) P. Adriaensens, L. Strome, R. Carleer and J. Gelan, Macromolecules 2002, 35, 3965; (i) W. Lequieu, P. Van De Velde, F. E. Du Prez, P. Adriaensens, L. Strome and J. Gelan, Polymer 2004, 45, 7943; (j) N. Bruns, J. C. Tiller, Nano Lett. 2005, 5, 45; (k) Z. K. Hu, L. Chen, D. E. Betts, A. Pandya, M. A. Hillmyer and J. M. DeSimone, J. Am. Chem. Soc. 2008, 130, 14244; (1) J. Tobis, L. Boch, Y. Thomann and J. C. Tiller, J. Membr. Sci. 2011, 372, 219; (m) L. Bromberg, M. Temchenko, T. A. Hatton, Langmuir 2002, 18, 4944; (n) M. Hanko, N. Bruns, S. Rentmeister, J. C. Tiller and J. Heinze, J. Anal. Chem. 2006, 78, 6376; (o) G. Kali, T. K. Georgiou, B. Iván, C. S. Ptrickios, E. Loizou, Y. Thomann and J. C. Tiller, Macromolecules 2007, 40, 2192; (p) G. Kali, T. K. Georgiou, B. Iván, C. S. Patrickios, E. Loizou, Y. Thomann, J. C. Tiller, Langmuir 2007, 23, 10746; (q) A. Domján, P. Mezey and J. Varga Macromolecules, 2012, 45, 1037; (r) K. Schöller, S. Küpfer, L. Baumann, P. M. Hoyer, D. de Courten, R. M. Rossi, A. Vetushka, M. Wolf, N. Bruns and L. J. Scherer, Adv. Funct. Mater. 2014, 24, 5194.

17 L. Costa, G. Camino, M. P. Luda, G. G. Cameron and M. Y. Qureshi, M. Y. Polym. Degrad. Stab. 1998, 62, 49.

18 R. P. Lattimer, J. Anal. Appl. Pyrolysis 2001, 57, 57.
19 F. D. Kopinke, M. Remmler and K. Mackenzie, Polym. Degrad. Stab. 1996, 52, 25.

20 (a) B. Plage and H.-R. Schulten, Macromolecules 1990, 23, 2642; (b) B. Plage and H.-R. Schulten, J. Anal. Appl. Pyrolysis 1989, 15, 197; (c) I. Lüderwald and H.Urrutia, Makromol. Chem. 1976, 177, 2079.

21 M. Rikkou-Kalourkoti, P. A. Panteli and C. S. Patrickios, Polym. Chem. 2014, 5, 4339. 